\title{
TU/e EN⿴HONE

\section{Suppression of tritium retention in remote areas of ITER by nonperturbative reactive gas injection}

\section{Citation for published version (APA):}

Tabarés, F. L., Ferreira, J. A., Ramos, A., Rooij, van, G. J., Westerhout, J., Al, R., Rapp, J., Drenik, A., \& Mozetic, M. (2010). Suppression of tritium retention in remote areas of ITER by nonperturbative reactive gas injection. Physical Review Letters, 105(17), 175006-1/4. [175006].

https://doi.org/10.1103/PhysRevLett.105.175006

DOI:

10.1103/PhysRevLett.105.175006

Document status and date:

Published: 01/01/2010

\section{Document Version:}

Publisher's PDF, also known as Version of Record (includes final page, issue and volume numbers)

\section{Please check the document version of this publication:}

- A submitted manuscript is the version of the article upon submission and before peer-review. There can be important differences between the submitted version and the official published version of record. People interested in the research are advised to contact the author for the final version of the publication, or visit the $\mathrm{DOI}$ to the publisher's website.

- The final author version and the galley proof are versions of the publication after peer review.

- The final published version features the final layout of the paper including the volume, issue and page numbers.

Link to publication

\section{General rights}

Copyright and moral rights for the publications made accessible in the public portal are retained by the authors and/or other copyright owners and it is a condition of accessing publications that users recognise and abide by the legal requirements associated with these rights.

- Users may download and print one copy of any publication from the public portal for the purpose of private study or research.

- You may not further distribute the material or use it for any profit-making activity or commercial gain

- You may freely distribute the URL identifying the publication in the public portal.

If the publication is distributed under the terms of Article 25fa of the Dutch Copyright Act, indicated by the "Taverne" license above, please follow below link for the End User Agreement:

www.tue.nl/taverne

Take down policy

If you believe that this document breaches copyright please contact us at:

openaccess@tue.nl

providing details and we will investigate your claim. 


\title{
Suppression of Tritium Retention in Remote Areas of ITER by Nonperturbative Reactive Gas Injection
}

\author{
F. L. Tabarés, ${ }^{1, *}$ J. A. Ferreira, ${ }^{1}$ A. Ramos, ${ }^{1}$ G. van Rooij, ${ }^{2}$ J. Westerhout, ${ }^{2}$ R. Al, ${ }^{2}$ J. Rapp, ${ }^{2}$ A. Drenik, ${ }^{3}$ and M. Mozetic ${ }^{3}$ \\ ${ }^{1}$ As Euratom-Ciemat, Av Complutense 22, 28040 Madrid, Spain \\ ${ }^{2}$ FOM Instituut voor Plasmafysica Rijnhuizen, EURATOM Association, TEC, PO Box 1207, 3430 BE Nieuwegein, The Netherlands \\ ${ }^{3}$ As Euratom-MHEST, Institut Jozef Stefan, Jamova cesta 39, 1000 Ljubljana, Slovenia
}

(Received 5 April 2010; published 22 October 2010)

\begin{abstract}
A technique based on reactive gas injection in the afterglow region of the divertor plasma is proposed for the suppression of tritium-carbon codeposits in remote areas of ITER when operated with carbonbased divertor targets. Experiments in a divertor simulator plasma device indicate that a $4 \mathrm{~nm} / \mathrm{min}$ deposition can be suppressed by addition of $1 \mathrm{~Pa} \cdot \mathrm{m}^{3} \mathrm{~s}^{-1}$ ammonia flow at $10 \mathrm{~cm}$ from the plasma. These results bolster the concept of nonperturbative scavenger injection for tritium inventory control in carbonbased fusion plasma devices, thus paving the way for ITER operation in the active phase under a carbondominated, plasma facing component background.
\end{abstract}

After decades of active research, the selection of plasma facing materials for locations of maximum particle and heat fluxes in a fusion reactor still remains as an open issue. This choice is particularly demanding for the final design of the divertor elements of the International Thermonuclear Experimental Reactor (ITER), presently under construction in Cadarache, France. To date, for the most extreme conditions, carbon materials have demonstrated the best performance in terms of plasma contamination and material degradation, basically due to the low atomic number, strong radiation capability, and excellent thermomechanical characteristics of carbon [1]. However, the use of carbon materials at the divertor plates of ITER during deuterium-tritium operation is strongly hampered by the formation of tritium-containing codeposits from the products of chemical sputtering [2]. These layers are also a potential source of dust formation, and the most recent estimates for the standard, carbon-tungsten divertor operation scenario indicate that the tritium inventory value of $1 \mathrm{~kg}$ used in safety assessments could be reached after a few hundred plasma pulses [3]. Unfortunately, carbontritium codeposits are found at remote areas from the plasma, with difficult access to plasma-based detritiation techniques [4].

Although several ideas have been put forward to solve this problem, all of them require specific time devoted to cleaning and, in some cases, to the recovery of plasma normal operation from the strongly perturbed first wall conditions originated by the procedure [5]. Of especial appeal are techniques capable of inhibiting the deposition of tritiated films during normal plasma operation, the scavenger concept being among them [6]. Initially based on the broad experience achieved in the field of plasma assisted chemical vapor deposition of nitrogen-carbon films [7], the technique has been tested in laboratory experiments in low temperature plasmas and under current divertor conditions in JET and Asdex Upgrade (AUG) $[8,9]$, with different success. Although subdivertor puffing in AUG achieved a suppression efficiency of carbon film deposition of $80 \%$, only a moderate reduction $(<30 \%)$ was seen at JET in type-III edge-localized mode (ELMy) discharges with strong nitrogen seeding, once allowance for the cooling effect of the injected species is made. To date, only nitrogen, which is highly suited for divertor radiation enhancement in present fusion devices [10], has been tested as a possible radical scavenger. The high carbon erosion rate observed under ionic nitrogenized species, with an anomalously low energy threshold [11], raises concern of enhanced erosion of the divertor plates when nitrogen is injected into the plasma periphery. Therefore, remote injection of scavengers in carbonradical rich areas prone to codeposit and dust formation would be desirable.

Recent experiments of nitrogen seeding at the PSI-2 linear plasma device [12] indicate that radical, as opposed to ion, chemistry plays the main role in the scavenger effect. Moreover, a possible direct reaction between ammonia, formed as a chemical product from the recombination of $\mathrm{N}$ and $\mathrm{H}$ atoms at the walls, and carbon radicals was deduced from mass spectrometric recordings. Compared with nitrogen, a well-known inert gas in its molecular form, ammonia shows high reactivity against radical species, and no need for plasma activation should exist. In this work, the first experiments of direct injection of ammonia as a carbon-radical scavenger in a divertor-type plasma are described.

The experiments were performed at the PILOT-PSI linear plasma device [13]. With respect to its standard configuration, the most important modification was the insertion of a hot stainless steel liner, coaxial to the plasma and with an inner diameter of $25 \mathrm{~cm}$. The temperature of the liner was kept at $\sim 300{ }^{\circ} \mathrm{C}$ in order to minimize local 
deposition of carbon and thus to enhance the transport of plasma-borne radicals to the deposition sample [14]. The sample consists of two polished silicon wafers, located downstream of the plasma and $\sim 7 \mathrm{~cm}$ behind the target. No direct line of sight was allowed between the plasma and the samples. Figure 1 shows a sketch of the setup. Carbon deposition was monitored in situ by laser interferometry [15] through a view port and a hole made in the liner. One of the samples was used as a reference of the naked $\mathrm{Si}$ reflectivity, and the other one was precoated with a $50 \mathrm{~nm}$ film layer in order to match the part of the interference pattern most sensitive to the film growth. The technique was calibrated by ex situ ellipsometry. A more detailed description of the experimental conditions used in the present work can be found in Ref. [16].

Hydrogen-methane plasmas were run at a total pressure of $P \sim 4 \mathrm{~Pa}$. Nitrogen and ammonia were used as scavengers. They were injected either into the plasma region or at the location of the deposition sample. Typical deposition rates at the Si sample, in the absence of a scavenger, were up to $4 \mathrm{~nm} / \mathrm{min}$. Optical emission spectroscopy and a differentially pumped mass spectrometer (MS) were used for the characterization of molecular species in the plasma.

Under initial constant $\mathrm{H}_{2} / \mathrm{CH}_{4}$ plasma composition, current, and total pressure conditions, the deposition rate at the sample was strongly modified by the addition of nitrogen or ammonia to the plasma. Some blank experiments were eventually run during the scans in scavenger flow to check for reproducibility. Even for pure $\mathrm{H}$ plasmas, a net deposition in the sample was eventually found. This is attributed to a memory effect, the erosion of carbon at the walls from previous depositions, and it was taken into account when comparing runs well separated in time. Nevertheless, a systematic decrease of the deposition rate upon increasing the nitrogen or ammonia concentration in the plasma in consecutive shots was observed.

The influence of gas injection location on the film inhibition effect was tested by using the gas pipe located in front of the deposition monitor for the scavenger inlet. A summary of the observed trends is shown in Fig. 2. The injected fluxes of scavenger shown in the abscissa were evaluated from the partial pressure recordings in the MS

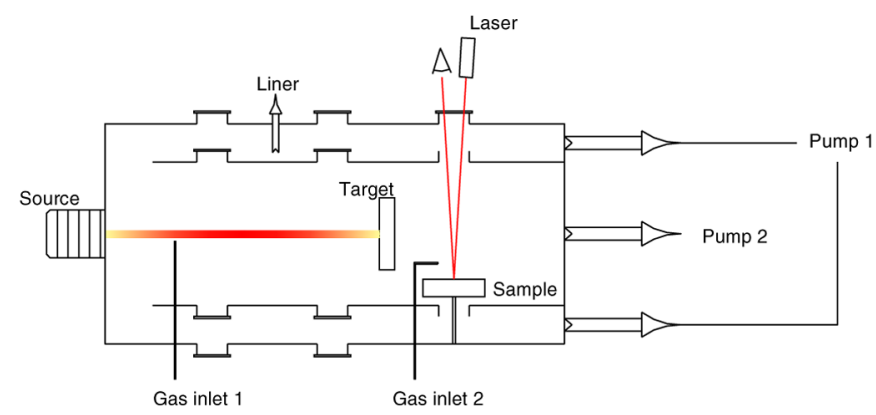

FIG. 1 (color online). Layout of the Pilot-PSI vacuum chamber with the setup used for the experiments (not to scale). for the corresponding species. Several important facts can be deduced from the plots. First, systematically higher flows of nitrogen than ammonia are required in order to achieve the same film inhibition effect. Moreover, no significant difference in the flux of ammonia demanded for a given effect is seen, regardless of inlet locations. This is not the case for nitrogen, where a factor of 2-3 higher flows are required if the gas is injected near the sample.

The observed differences between both types of scavengers can be tracked back to their intrinsic molecular reactivity with the carbon film precursor. Thus, while molecular nitrogen is a highly inert species, if not "activated" by the plasma, ammonia and its related radicals have a strong affinity with methyl radicals, believed to be the main long-range carbon-transporting species, leading to the fast reactions of the type [17]

$$
\mathrm{NH}_{3}+\mathrm{CH}_{3} \rightarrow \mathrm{HCN}+2 \mathrm{H}_{2}+\mathrm{H}
$$

and

$$
\mathrm{NH}_{2}+\mathrm{CH}_{4} \rightarrow \mathrm{HCN}+2 \mathrm{H}_{2}+\mathrm{H} \text {. }
$$

Although these reactions were suggested as possible candidates, among others, for the observed inhibition of $\mathrm{C} / \mathrm{N}$ deposits in hot filament chemical vapor deposition reactors [17], no evidence of their actual relevance has been reported so far.

When compared with other species present in the cold plasma, HCN shows very high stability (C-N bonding energy is $8.15 \mathrm{eV}$ while $\mathrm{N}-\mathrm{H}$ is $3.6 \mathrm{eV}$ ). Therefore it is highly likely that, within the restricted residence time in the plasma, it will undergo negligible cracking. In Fig. 3, the recorded intensity of the corresponding mass, amu 27,

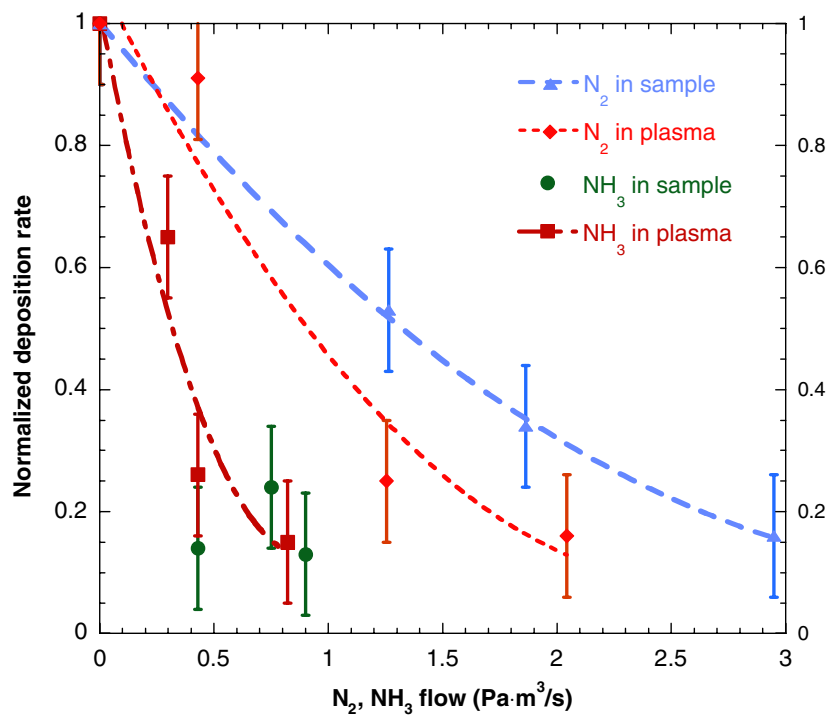

FIG. 2 (color online). Dependence of the normalized deposition rate of carbon on injected scavenger at two different gas inlet locations: circles, in sample; squares, in plasma. Errors are mainly due to the reference deposition rate value. 


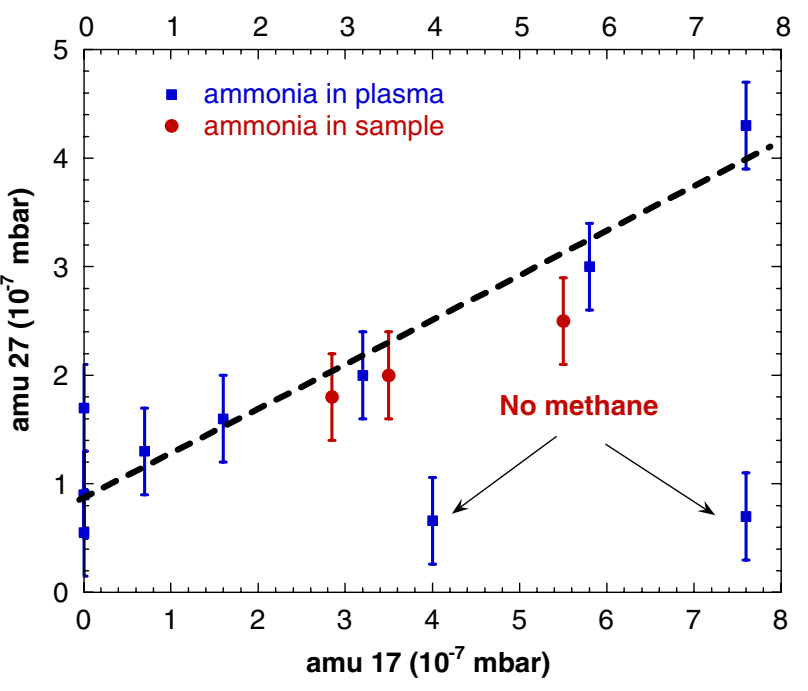

FIG. 3 (color online). $\mathrm{HCN}$ (amu 27) formation by ammonia injection at two different locations.

is plotted against the amount of injected ammonia in the plasma. As expected, an increase in mass 27 is only seen when both methane and ammonia are simultaneously injected, which precludes any significant contribution from ethylene to the amu 27 peak [18]. At constant methane concentration in the plasma, the increase of $\mathrm{HCN}$ is proportional to the injected ammonia, no matter where the injection is made. All these findings stress the minor role that plasma activation plays in the scavenging efficiency of ammonia, in stark contradiction with the nitrogen behavior [12].

In the observations addressed above, a constant source of carbon film precursor was assumed for all plasma conditions. The cracking of methane in the plasma can be readily followed by mass spectrometry and through the associated emission of excited $\mathrm{CH}$ radicals [19]. In the recorded optical emission spectra of the different plasmas, new bands appear upon the injection of any of the scavenger species, nitrogen or ammonia, corresponding to the violet system of CN. A signal increment at $\sim 390 \mathrm{~nm}$ with respect to the methane plasma is always seen, being slightly larger with $\mathrm{NH}_{3}$ than with $\mathrm{N}_{2}$ for any injection case. However, no significant changes in the intensity of the $\mathrm{CH}(A-X)$ molecular band are detected in the experiments, as expected under unperturbed scavenger injection conditions. From the optical emission spectroscopy data, it is concluded that there is a weaker plasma-ammonia interaction when the injection is located at the sample, while its scavenging effect on the carbon deposition is basically unchanged, as shown in Fig. 2.

The difference in scavenger effectiveness of nitrogen when compared to ammonia is not surprising if reactions (1) and (2) above are assumed to be the main mechanism. Moreover, one may think that the role of nitrogen in the hydrogen-methane plasma is to provide molecular ammonia, which actually plays the chemical role. Indeed, the amount of HCN produced by the different plasmas was found directly proportional to the ammonia concentration, regardless of whether directly injected or produced from atomic recombination in the $\mathrm{N}_{2} / \mathrm{H}_{2}$ plasmas [16]. It must be pointed out that this plasma induced synthesis was observed in previous Ciemat experiments only under a partially carbon covered reactor wall, as foreseen for ITER remote walls, being replaced by strong acetylene formation under full carbon coverage conditions [20].

In order to assess the presence of reaction (1) under conditions free from possible scavenger plasma interaction, a different experiment was envisaged. A rf plasma, with a high dissociation efficiency for methane, was created in a Pyrex chamber at $p=20 \mathrm{~Pa}$ and $P_{\text {in }}=120 \mathrm{~W}$. This chamber was connected through a narrow tube ( $l=40 \mathrm{~mm}, \phi=3 \mathrm{~mm}$ ) to a downstream region where ammonia was directly seeded, as displayed in Fig. 4. The absence of $\mathrm{CN}$ emission verifies the absence of backdiffusion into the methane plasma. A differentially pumped mass spectrometer was again used for the monitoring of plasma conditions and the ammonia flow was swept while the MS peaks at amu 25-30 were recorded. Contrary to the Pilot-PSI experiments, a significant production of $\mathrm{C}_{2}$ hydrocarbons was detected in the absence of ammonia, created by the recombination of $\mathrm{CH}_{x}(1 \leq x \leq 3)$ radicals from the cracking of methane into the plasma. The absence of film deposition into the reactor walls was taken as evidence of optimized gas phase concentration of free $\mathrm{CH}_{x}$ radicals. The reconstruction of the reaction product composition from the recorded mass spectra was possible due to the lack of contribution of $\mathrm{HCN}$ to mass 25 and the known intensities of the MS peaks from the ionization of $\mathrm{C}_{2} \mathrm{H}_{x}$ hydrocarbons into the mass spectrometer [18], experimentally verified for the analysis reported here. The results of the scan in ammonia pressure, referred to as the intensity of amu 17 in the MS, are displayed in Fig. 5. The direct contribution to amu 27 by pure ammonia (plasma off) is also shown for comparison. The data displayed support the presence of two competing processes: $\mathrm{CH}_{x}$ recombination to yield $\mathrm{C}_{2} \mathrm{H}_{y}$ hydrocarbons and

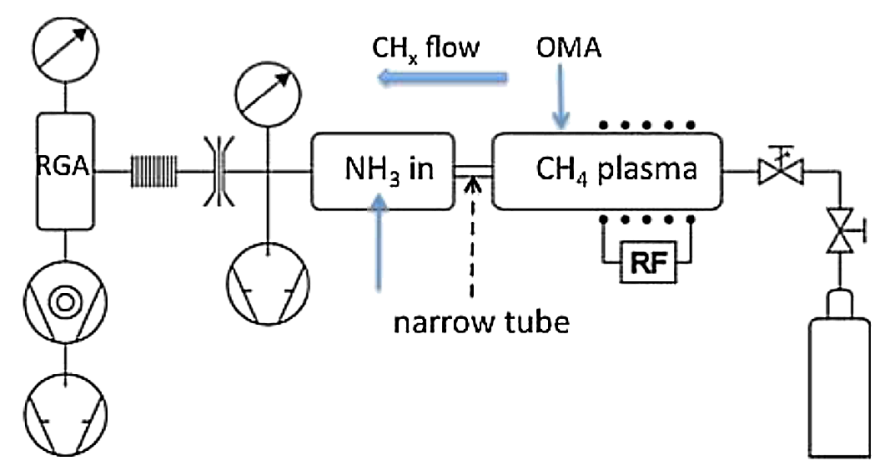

FIG. 4 (color online). Layout of the rf plasma reactor used for $\mathrm{CH}_{3}$-ammonia interaction experiments. RGA: residual gas analyzer, OMA: optical multichannel analyzer. 


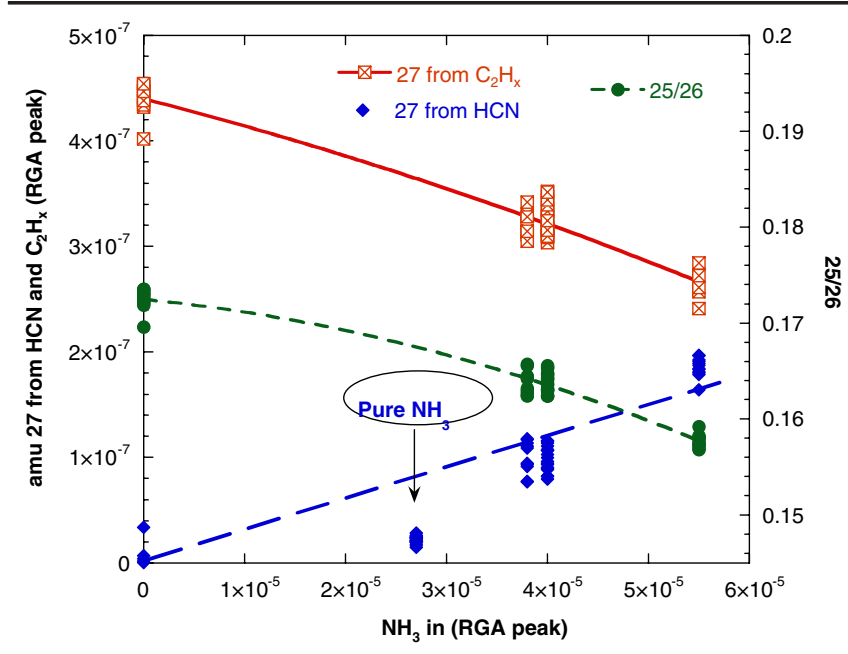

FIG. 5 (color online). Formation of $\mathrm{C}_{2} \mathrm{H}_{x}$ hydrocarbons and $\mathrm{HCN}$ at different ammonia flows injected downstream of a rf methane plasma. The contribution to amu 27 in the mass spectrometer from the two species is deduced form the recorded peaks at amu 25-30. Lines are shown only for clarity.

scavenging of $\mathrm{CH}_{x}$ radicals by ammonia to yield $\mathrm{HCN}$. The larger extent of reaction (1), as ammonia is increased, leads also to a continuous drop of the ratio $25 / 26$, as shown in Fig. 5. Also, the fact that no saturation in the reconstructed HCN concentration at the highest ammonia flow is seen indicates that the reaction is still limited by the available scavenger supply. Therefore, a more quantitative analysis of this reactive system would be required for the assessment of the required ammonia flow in a fusion device.

When implementing the proposed technique in ITER, the impact of ammonia injection on divertor plasmas, in-vessel components, and cryopumps must be properly evaluated. Of particular concern could be poisoning the zeolites at the main cryopumps, strictly required for an efficient He pumping [21]. Although addressing these details is out of the scope of this Letter, some considerations are worth taking into account. First, both ammonia and $\mathrm{HCN}$ are species readily condensed at liquid nitrogen temperature. Therefore they could be trapped into a $\mathrm{LN}_{2}$ shield well before they reach the $4 \mathrm{~K}$ area of the cryopump. Secondly, ammonia is easily decomposed by the scavenger reaction itself, as deduced from the results presented above. Moreover, the presence of a directional flow towards the pump will add up to the chemical removal. Finally, its high dissociation rate in the weak afterglow plasma makes any disturbance of the divertor plasma highly unlikely. If the present estimates of net eroded carbon flowing into the remote areas are assumed [22], required ammonia fluxes of $<5 \mathrm{~Pa} \cdot \mathrm{m}^{3} \mathrm{~s}^{-1}$ can be anticipated in ITER, i.e., in the low range of those proposed for radiation cooling of the divertor plasma [23]. Tritium recovery from the involved species, $\mathrm{NHT}_{x}$ and TCN, by thermal decomposition of the defrost $\mathrm{LN}_{2}$ trap outcome also seems feasible based on the known characteristics of these molecules [24]. Therefore, we conclude that pure ammonia injection in the plasma afterglow of ITER bodes well for suppressing film formation in remote areas, as required for tritium inventory control under carbon $\mathrm{PFC}$ scenarios. The outcome of the reaction, HCN, could be easily trapped under liquid nitrogen temperatures and then reprocessed for tritium recovery. These technical details, including a more quantitative estimate of the absolute values for the required flows within the present uncertainties [22], will be addressed in the future.

Part of this work was financially supported by the Spanish Ministry of Science and Innovation, under Project ENE2006-14577-C04-01, Slovenian Research Agency under Project P2-0082, and by EFDA under the Technical Task WP09-PWI-02-02.

*tabares@ciemat.es

[1] G. Federici and C.H. Skinner, in Nuclear Fusion Research: Understanding Plasma-Surface Interactions, edited by R.E.H. Clark and D.H. Reiter (SpringerVerlag, Berlin, 2005), p. 294.

[2] G. Federici et al., Nucl. Fusion 41, 1967 (2001).

[3] J. Roth et al., Plasma Phys. Controlled Fusion 50, 103001 (2008).

[4] A. Kreter et al., Phys. Rev. Lett. 102, 045007 (2009).

[5] G. Counsell et al., Plasma Phys. Controlled Fusion 48, B189 (2006).

[6] F. L. Tabares et al., Plasma Phys. Controlled Fusion 44, L37 (2002).

[7] F. L. Tabares and V. Rohde, Plasma Phys. Controlled Fusion 46, B381 (2004).

[8] F. L. Tabares et al., J. Nucl. Mater. 337-339, 867 (2005).

[9] F. L. Tabares and V. Rohde, Nucl. Fusion 45, L27 (2005).

[10] J. Rapp et al., J. Nucl. Mater. 337-339, 826 (2005).

[11] W. Jacob et al., Appl. Phys. Lett. 86, 204103 (2005).

[12] W. Bohmeyer et al., J. Nucl. Mater. 390-391, 560 (2009).

[13] J. Westerhout et al., Phys. Scr. T128, 18 (2007).

[14] W. Bohmeyer et al., in Proceedings of the 30th EPS Conference on Controlled Fusion and Plasma Physics, St. Petersburg, FL, 2003, ECA, Vol. 27A, Session P-3.184, http://epsppd.epfl.ch/StPetersburg/start.html

[15] W. L. Hsu, J. Vac. Sci. Technol. A 7, 1047 (1989).

[16] F.L. Tabares et al., Proceedings of the 19th PSI Conference, San Diego, 2010 (to be published).

[17] P. W. May et al., Diam. Relat. Mater. 5, 354 (1996).

[18] NIST Chemistry WebBook, Database Number 69, edited by P. J. Linstrom and W. G. Mallard (National Institute of Standards and Technology, Gaithersburg, MD, 2010).

[19] S. Brezinsek et al., J. Nucl. Mater. 363-365, 1119 (2007).

[20] J. A. Ferreira and F. L. Tabares, Plasma Sources Sci. Technol. 18, 034019 (2009).

[21] A. Mack et al., Fusion Eng. Des. 61-62, 611 (2002).

[22] See, for example, A. Kirschner et al., J. Nucl. Mater. 390-391, 152 (2009).

[23] R. Zagorski et al., Contrib. Plasma Phys. 48, 179 (2008).

[24] Ullmann's Encyclopedia of Industrial Chemistry (John Wiley \& Sons, New York, in press), 7th ed. 